\title{
2. The view from the Baltic Sea Region
}

\section{CONTEXTUAL FRAME AND TRENDS OF REGIONAL COOPERATION AND INTEGRATION IN THE BALTIC SEA REGION}

As part of its efforts to develop a second generation of RCI policies, the Asian Development Bank (ADB) draws insights from comparable efforts in other areas of the world. The purpose of this chapter is to provide a perspective on how regional integration across the BSR has developed over the last few decades. This chapter outlines how BSR economies have leveraged RCI drivers of productivity. Following the Baltic Sea Region experience, greater regional integration strengthens tendencies to agglomerate economic activity in clusters. In consequence, BSR economies have avoided productivity slowdown throughout the global financial crisis years, which is rather unique in the global comparative RCI experience. This discussion helps us assess how policies, data and knowledge platforms designed to support the economic integration process across the BSR might be successfully leveraged in Asia.

Again, unique in global comparative RCI experience, the BSR has continuously narrowed the dispersion of welfare. Cohesion and innovation policies have been successfully implemented. As the example of the Baltic Sea Region shows, European (inclusionary) cohesion policies undertaken on national levels can be influenced by regional consensual coordination mechanisms. This is implemented effectively in the BSR through an innovation steering group. Horizontal policy coordination can work by setting common goals in terms of regional technology platforms, innovation cluster networks, diagnostic and indicator-based tools and infrastructure. It can help develop free movement of researchers, knowledge and technology across a region. The chapter highlights lessons learned that may be applicable to the Asian context for inclusionary policies.

At its core, the Baltic Sea Region includes the Nordic countries (Denmark, Iceland, Finland, Norway and Sweden) as well as the Baltic countries (Estonia, Latvia and Lithuania). It also includes parts of Germany, Poland and the Russian Federation. Efforts to support regional integration across the Baltic Sea Region have gone through a number of 
phases over the last 25 years, largely driven by changes in the economic context, which, in turn, have shifted the needs of governments and economies across the region.

The EU Summit in Copenhagen in 1993 opened the door for Central and Eastern European countries to become members of the EU. A first step was taken with the Europe Agreement signed in 1995 (in effect from 1998) that created free trade and strong political ties. The same year the Baltic countries and Poland applied for full membership in the EU. Membership negotiations were concluded in 2002, and on 1 May 2004 the Baltic countries and Poland joined (together with seven other countries) the European Union. The Baltic Sea had turned from a borderline in the East-West conflict to a sea almost entirely surrounded by EU members. As an informal group, the Nordic and Baltic EU member countries created the North Baltic-(NB-)6 to coordinate their positions in the European Council and other EU bodies.

Once EU membership had been achieved, the focus shifted to implementing EU rules and regulations, in particular the Common Market, across the region. Most of the instruments and programs were available at the entire EU level, not with a particular focus on the Baltic Sea Region. For example, all countries in the region were eligible for participation in joint projects under the framework programs for research, as well as several company-focused programs, including the services offered through the European Enterprise Network. Nearly $€ 80$ billion ( $\$ 86.5$ billion) from European Structural Funds ${ }^{1}$ were invested in the Baltic countries and Poland during the period 2007-13 (see Table 2.1 for details). A large portion of these funds targeted improvements in transport infrastructure (30 percent) and measures to protect and improve the environment (22 percent). Approximately 17 percent targeted measures to support R\&D and innovation, and less than 5 percent targeted business and entrepreneurial support measures. EU members also had access to the funds provided by the European Investment Bank, which, at the time, had a total lending portfolio of about $€ 45$ billion ( $\$ 48.6$ billion). In parallel, the Baltic countries in 2005 also became co-owners of the Nordic Investment Bank, creating easier access to its long-term credit offering.

While many programs had a financial dimension, the EU also offered a wide range of technical support mechanisms and knowledge platforms, covering many aspects of policy making and tracking innovation and economic performance. Examples include support to development of regional innovation strategies, policy learning activities (for example, study visits, regional twinning exercises, and a series of InnoNet ${ }^{2}$ projects), and regular innovation scoreboards (on regional and national levels). The first attempt at systematically mapping the presence of clusters was, for 


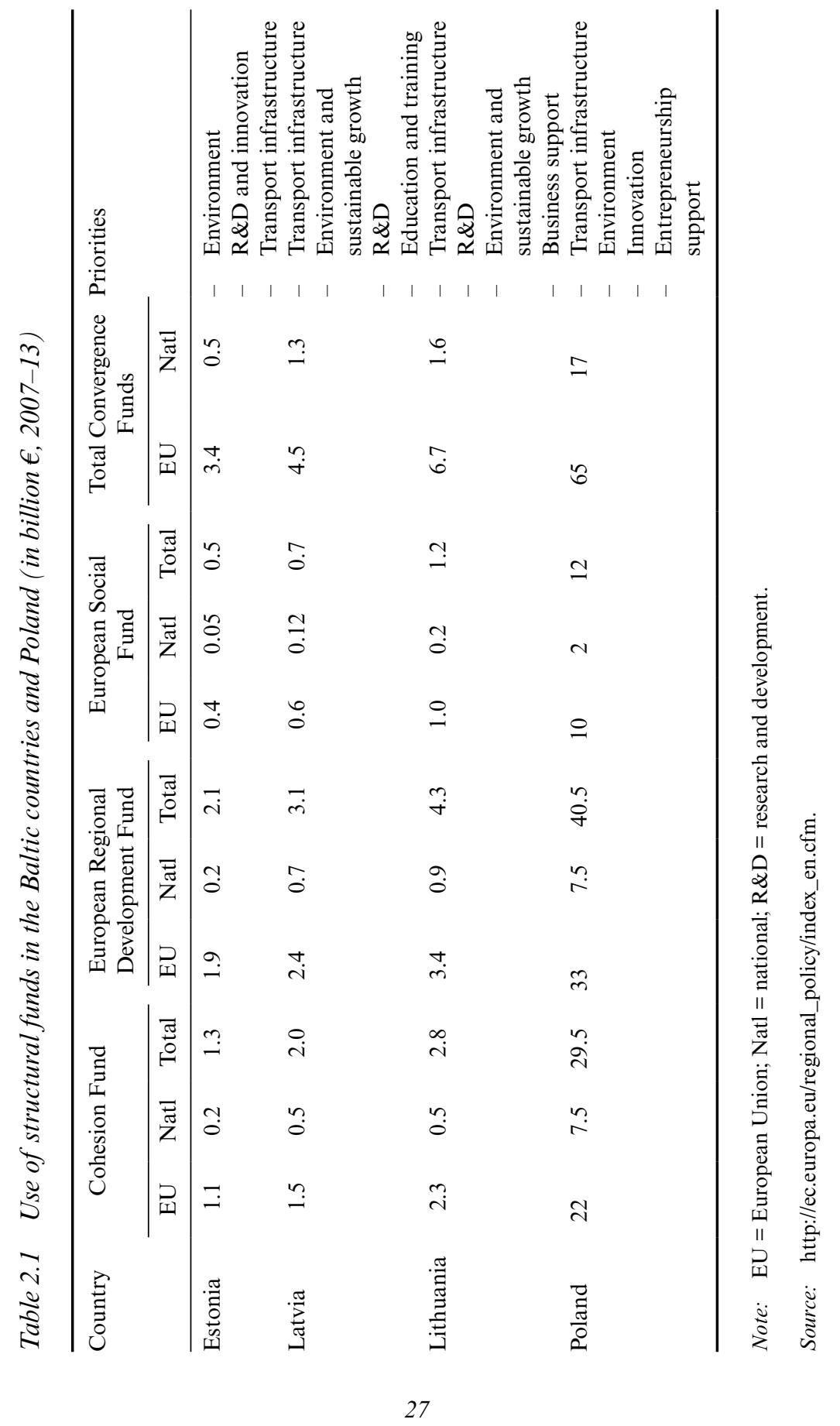


example, initiated under the context of the Europe INNOVA program. ${ }^{3}$ The European Cluster Observatory later provided options to look specifically at the clusters across the Baltic Sea Region.

Most of the EU programs did not have a specific focus on cross-border collaboration within a region; the implicit principle was to avoid creating a Europe of subgroups. The only exception was the INTERREG program, which had a much smaller budget than the national structural fund programs to which it was related. The INTERREG program for the Baltic Sea Region was developed by the eight EU member states of Denmark, Germany, Estonia, Finland, Latvia, Lithuania, Poland and Sweden in close cooperation with the three non-member states, Belarus, Norway and the Russian Federation, and adopted on 21 December 2007 by the European Commission.

In about 2007, a group of EU parliamentarians, largely from the Baltic Sea Region, started to talk about the need for a dedicated EU policy for the region. During the Swedish EU Presidency at the end of 2007, the European Council invited the European Commission to develop a strategy for the Baltic Sea Region. In October 2009, this strategy was adopted, including a regularly updated action plan of about 80 flagship projects. The strategy would then provide orientation for everyone actively engaged in regional integration, and that way create a more mutually reinforcing set of activities. The existing EU instruments would be fully integrated and aligned with the objectives of the strategy. Two key choices made at the outset were to create no new institutions and to dedicate no new or separate budget for the strategy. In March 2012, following an interim report in 2010 and the first implementation report in the summer of 2011, the European Commission published a communication that responded to a request from the EU's General Affairs Council to review the EU Baltic Sea Region Strategy. Further 'meta-regional strategies' were launched in other parts of the EU.

The EU Strategy for the Baltic Sea Region (EUSBSR) turned out to be effective in aligning cross-regional activities in economic development, the environment and other areas. The strategy provided a stronger set of priorities than had existed before. It also encouraged the collaboration of all regional entities that had an interest in a specific topic. There were also interesting new efforts, like the BSR Stars project in the area of innovation and cluster-based economic development. Building on a number of collaborative initiatives among innovation policy makers and agencies before the launch of the EUSBSR, BSR Stars was adopted in the action plan as a 'fast-track' flagship within the priority area of innovation. BSR Stars aims to strengthen competitiveness and economic growth in the Baltic Sea Region by fostering transnational linkages between specialized research 
and innovation nodes, leading to new collaborations that can deliver new products, services and business models for global markets. ${ }^{4}$

This overall structure to govern the EU Baltic Sea Region Strategy affected the way specific activities undertaken as part of the strategy were aligned with each other. The two informational and analytical tools (the European Cluster Observatory (ECO) and the European Observation Network for Territorial Development and Cohesion (ESPON)), which provide territorial evidence as input to policy making, do not operate together and are not actively used as an input to policy development processes on the macro-regional level. The Priority Area Innovation (PA INNO) Steering Group, which has the mandate for establishing strategic policy objectives and priorities at the macro-regional level, is linked to the operational level and to the joint Baltic Sea research program (BONUS) through its flagships (including BSR Stars). Yet there are much weaker links with other instruments that are in the scope of other priority areas (as the Baltic University Program is linked to the Priority Area for Education), or with instruments that are implemented at the EU level (such as the European Cluster Excellence Initiative). The various instruments are part of different governing frames. The EU Strategy for the Baltic Sea Region has improved the alignment and strategic focus within the macro-regional structure, particularly for those activities that have a primary focus on regional integration. But significant challenges remain, especially in connecting activities with broader ambition on national or local business environment conditions to the integration agenda.

The overall governance structure provides the context for an overall strategy that can align individual activities and set measurable goals to track impact. On aligning activities, the EU Strategy for the Baltic Sea Region has led to significant progress. The definition of overall objectives, further broken down into specific ambitions by objective area, has given orientation to the many organizations and projects operating in the region. This has led to a more coherent set of actions, promising more impact and effectiveness. With regard to setting measurable goals, progress has been more limited. Given the fact that most regional integration instruments in the BSR case have operated in separate policy and governance frames, there is no overarching framework or indicators to conceptualize the link between individual initiatives, priority area targets and progress toward the longer-term goals. Most indicators for tracking progress (such as number of engaged companies and politicians, amount of add-on financing secured, launch of a new database, implementation of a matchmaking event and so on) exist on a project level, and on a broader, macro effect level (with indicators and/or trends monitored in the EU's Innovation Union Scoreboard, in BSR State of the Region Reports and so on). 
However, the lack of any dedicated funds and a strong governance structure turned out to be a challenge. The strategy process increasingly focused on activities directly related to interregionally financed projects or national efforts with a dedicated regional angle. It failed to engage a much broader set of activities that had a preliminary national focus but could have been opened up to include other parts of the region. The lack of a clear governance structure left the work without strong political leadership, handing the management to a group of high-level public officials that had a limited political mandate to move beyond the traditional areas of collaboration. A communication by the European Commission in 2014 tackled the governance issues of the strategy, and recommended that more responsibilities should be shifted from the Commission to member countries in the region.

The BSR is now home to close to 60 million people. About 43 percent of the region's inhabitants live in the Nordics, 12 percent in the Baltics, and the remainder in the parts of Germany, Poland and the Russian Federation bordering the Baltic Sea. Total employment in the region is at 28 million employees. In 2013 the region created an annual gross domestic product (GDP) adjusted for purchasing power parity (PPP) of around $€ 1.3$ trillion ( $\$ 1.4$ trillion). The Nordic countries account for 62 percent of the total. Northern Germany accounts for roughly 14 percent, followed by northwest Russian Federation's 12 percent. The Baltics contribute 7 percent and Northern Poland the remaining 5 percent.

The Baltic Sea Region has, over the last 25 years, become a strongly integrated economic space. For regions interested to learn from the BSR experience, it is important to review the evidence with regard to the following questions, with multiple linkages in terms of trade (Figures 2.1 to 2.3), investment (Figures 2.4 and 2.5), labor mobility (Table 2.2) and research collaboration (Figure 2.6).

- How critical has regional integration been for the economic performance of the Baltic Sea Region?

- What factors have been important in making regional integration possible and effective?

A rich structure of cross-border organizations and collaborative efforts supports and further develops these linkages. The region has over this period seen robust catch-up from the Baltic countries and Poland, even when the prosperity differences across the region remain large (Figures 2.7 to 2.9). And it is (with the Nordics) home to a number of countries that regularly rank among the most prosperous and competitive in the world.

To answer the first question ('How critical has regional integration been for the economic performance of the BSR?'), one has to look at direct and 


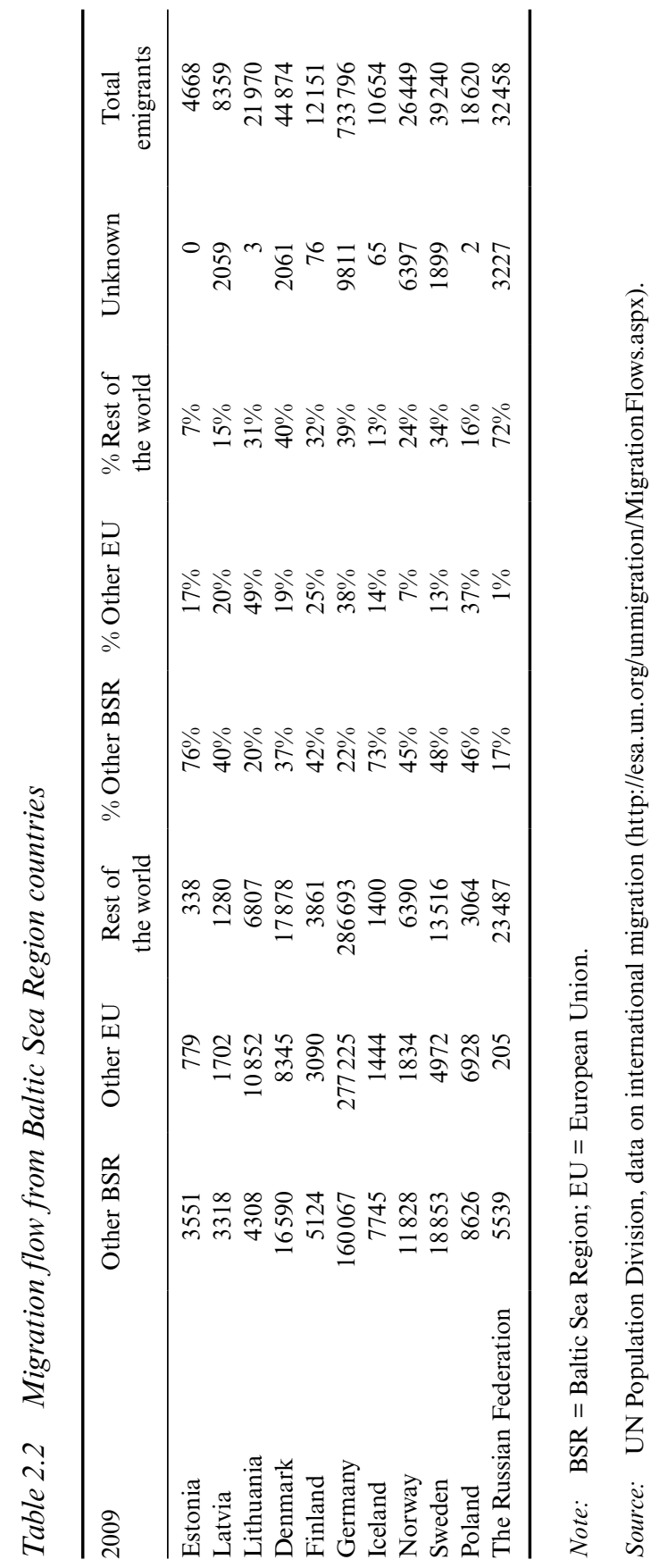




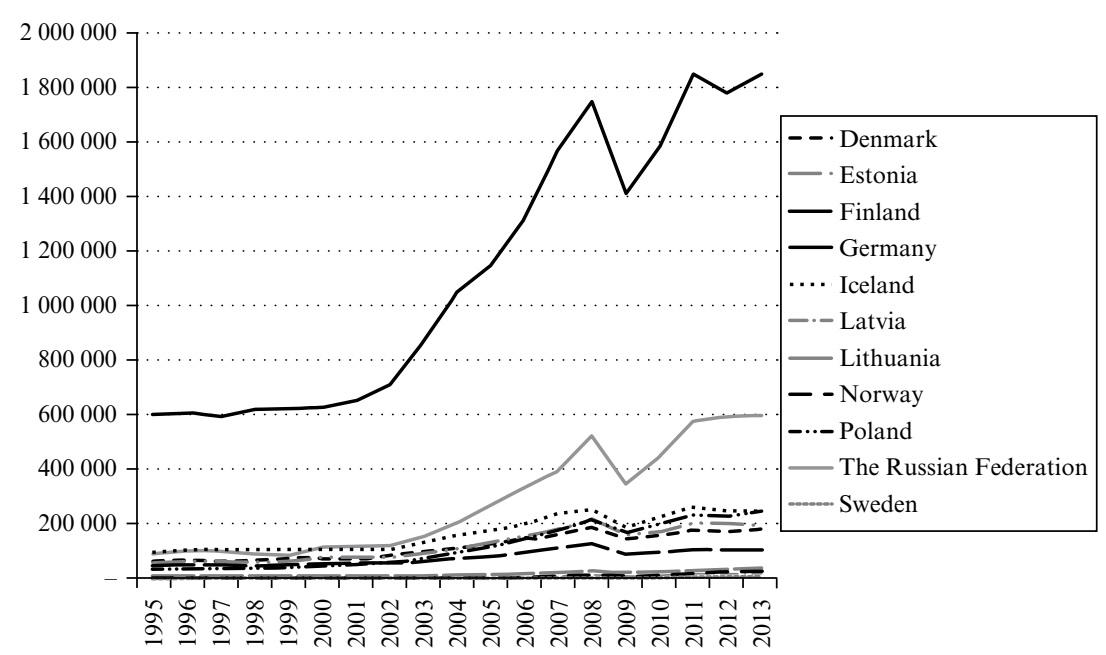

Source: UNCTADstat (2014), Goods and Services Trade Openness Indicators (http:// unctadstat.unctad.org/wds/ReportFolders/reportFolders.aspx).

Figure 2.1 Total exports of Baltic Sea Region countries (US\$ million)

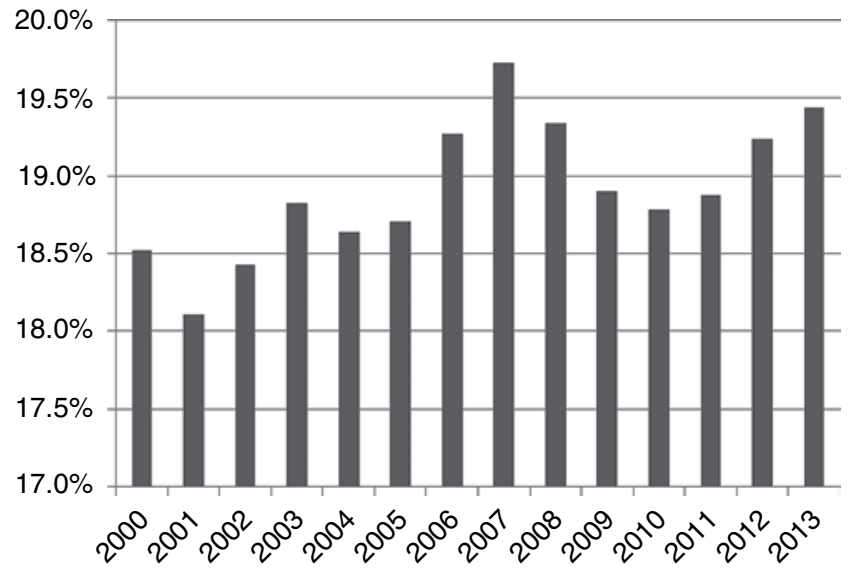

Source: UNCTADstat, Merchandise Trade matrix (http://unctadstat.unctad.org/ ReportFolders/reportFolders.aspx), Merchandise Trade, UNCTADstat (2014).

Figure 2.2 Intra-Baltic Sea Region exports as a share of total Baltic Sea Region exports 


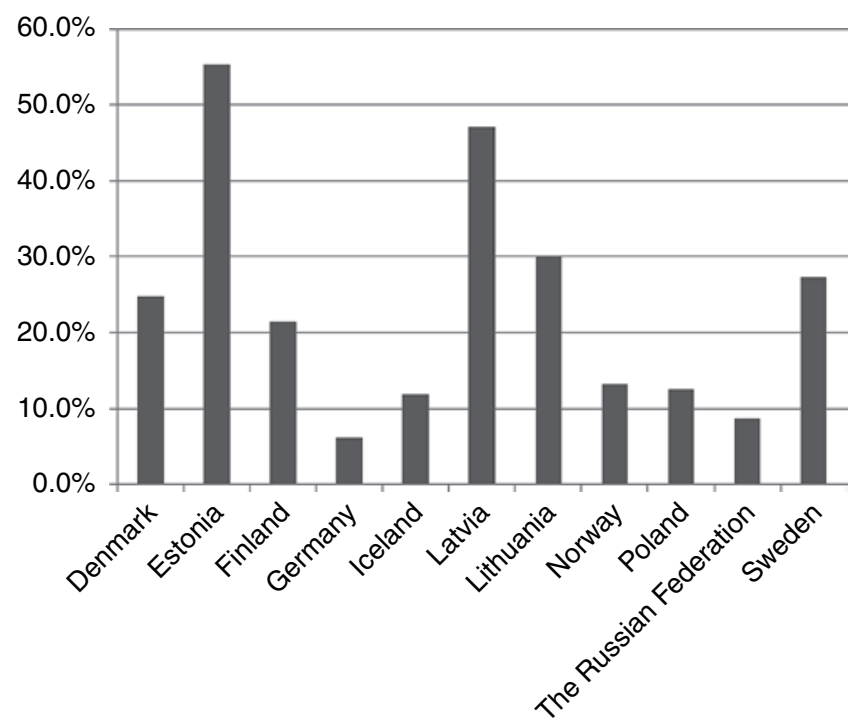

Source: UNCTADstat, Merchandise Trade matrix (http://unctadstat.unctad.org/ ReportFolders/reportFolders.aspx), Merchandise Trade, UNCTADstat (2014).

Figure 2.3 Share of 2013 exports to other Baltic Sea Region countries

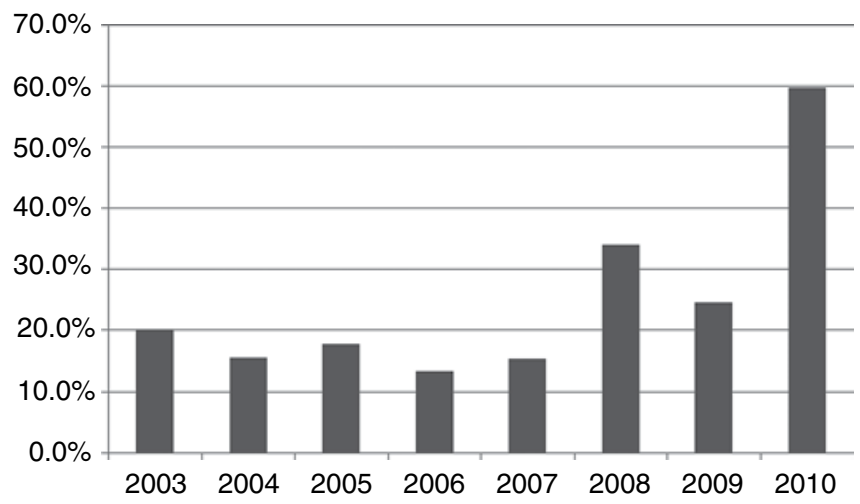

Source: OECD.stat (http://stats.oecd.org/), Foreign Direct Investment Flows by Partner Country, OECD.stat (2014).

Figure 2.4 Intra-Baltic Sea Region inward foreign direct investment as share of total inward foreign direct investment 


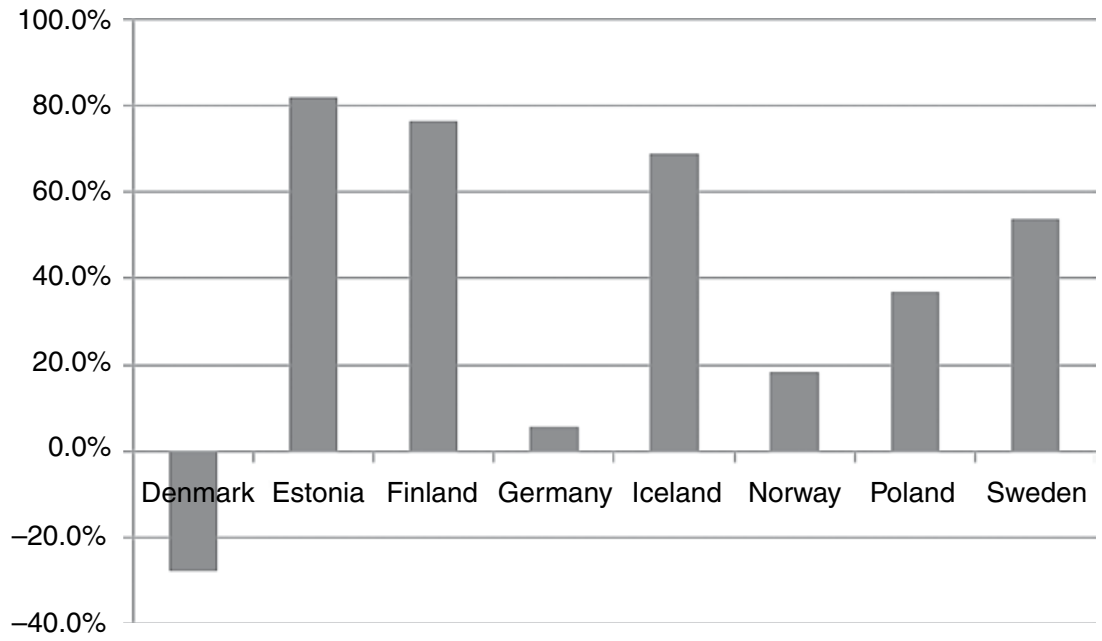

Source: OECD.stat (http://stats.oecd.org/), Foreign Direct Investment Flows by Partner Country, OECD.stat (2014).

\section{Figure 2.5 Share of 2012 inward foreign direct investment from other} Baltic Sea Region countries

indirect effects of regional integration. The direct effects, in the form of trade, investment and other linkages between the countries of the region (see Figure 2.10) have clearly been meaningful. Especially for the Baltic countries, these type of economic activities account for an important part of their overall trade and foreign investment relationships. They also quickly infused modern management techniques and a functioning, robust financial system to support the domestic economy. For the rest of the region, however, trade and investment across the Baltic Sea are often less critical. And, where they are the most important, they are more bilateral, occurring with direct neighbors rather than with the region as an overall entity.

One important factor that helps put these direct economic benefits into context is the comparison between the actual level of integration reached and the hypothetical level of integration expected, given prosperity levels, proximity and other relevant factors. The academic literature seems to suggest that the level of integration in the Baltic Sea Region is broadly in line with the predictions. This provides no clear indication that regional collaboration should have benefited the region through a higher level of direct economic integration. It remains true, for example, that companies 


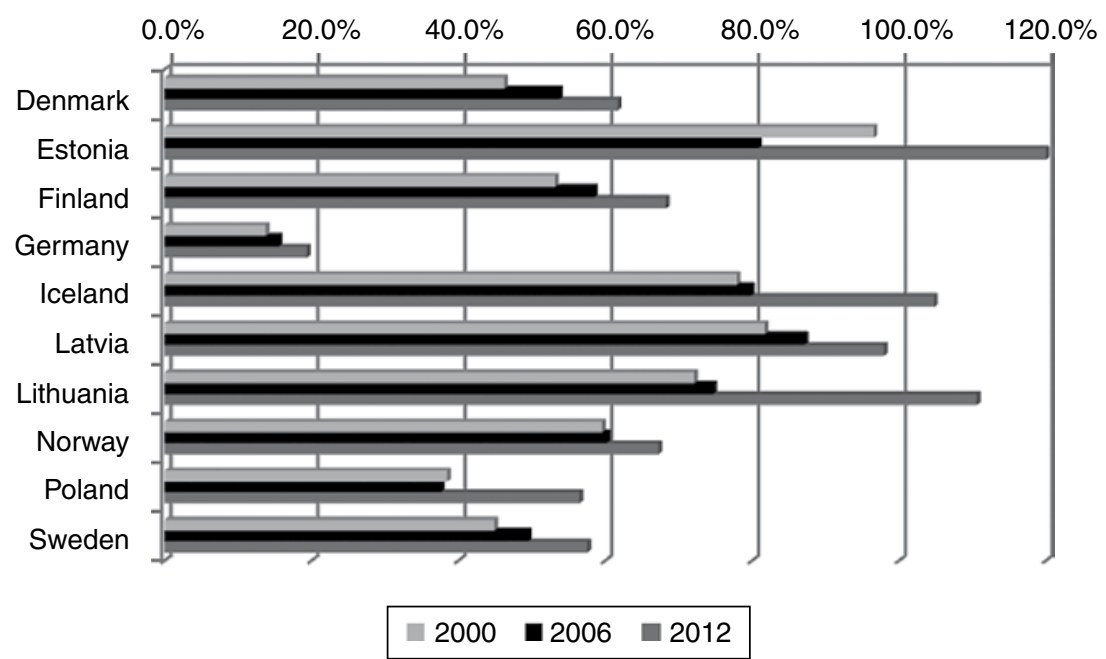

Note: International co-publications are determined based on the address of the authors. The fact that the percentage of intra-Baltic Sea Region co-publications exceeds 100 percent in 2012 (for Estonia, Iceland and Lithuania) is probably because there were multiple authors from the country.

Source: Thomson Reuters Web of Science (http://wokinfo.com/). Access for registered users only.

\section{Figure 2.6 International co-publications with other Baltic Sea Region countries (as share of total international co-publications)}

do not look at the Baltic Sea Region as one integrated market in terms of their strategies. For most of them, the region remains a group of individually small markets within the EU, each with its own dynamics, rivals and often even regulatory rules.

The indirect effects - in the form of creating an environment in which domestic policy reforms that enable growth and more effective integration with neighbors and the global economy are more likely - are much harder to measure, but potentially much more important. Some of this happens by creating higher economic returns for domestic reforms in the form of the direct benefits discussed above. Other changes happen through a combination of contractual commitments, peer pressure, learning, and access to technical and financial support within the context of regional collaboration. How critical both of these factors are depends on the level of political willingness and administrative capacity that already exists domestically, and the direction of change that the regional structures and/ or tools support (see Figure 2.11). 


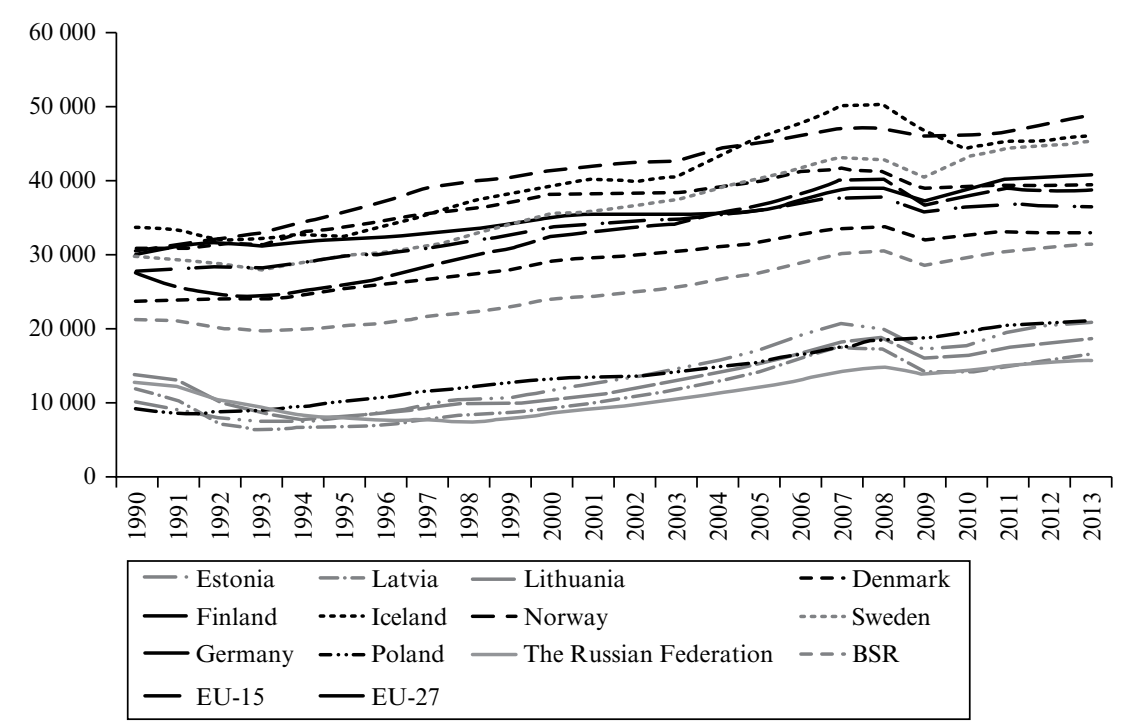

Note: $\quad$ BSR $=$ Baltic Sea Region; EKS $=$ Estonian Kroons; EU = European Union.

Source: Total Economy Database, The Conference Board.

Figure 2.7 Prosperity (gross domestic product per capita, in 2013 EKS)

The case of the Russian Federation illustrates how these direct and indirect effects are, in practice, interrelated. The direct level of economic integration with the Russian Federation's northwestern region and the rest of the Baltic Sea Region is much lower than in the region otherwise and lower than predicted by standard proximity models. This is likely to be driven by both higher trade and investment barriers between the Russian Federation and the rest of the region, and by the business environment conditions and lack of economic policy reforms in the Russian Federation itself. Regional integration can strengthen efforts to upgrade domestic competitiveness and enhance their returns, but without these domestic efforts neither are regional integration efforts likely to develop, nor will they have a strong impact on regional economic relations if they do.

The remainder of this chapter contains four sections. The first section details the interconnected layers of policy tools, how they stack up and connect for effect. The next section then details the indicator and measurement system of the interconnected layers of policy tools, and how they have come out in measuring BSR regional integration progress, for instance, in terms of innovation-driven productivity growth and increases 


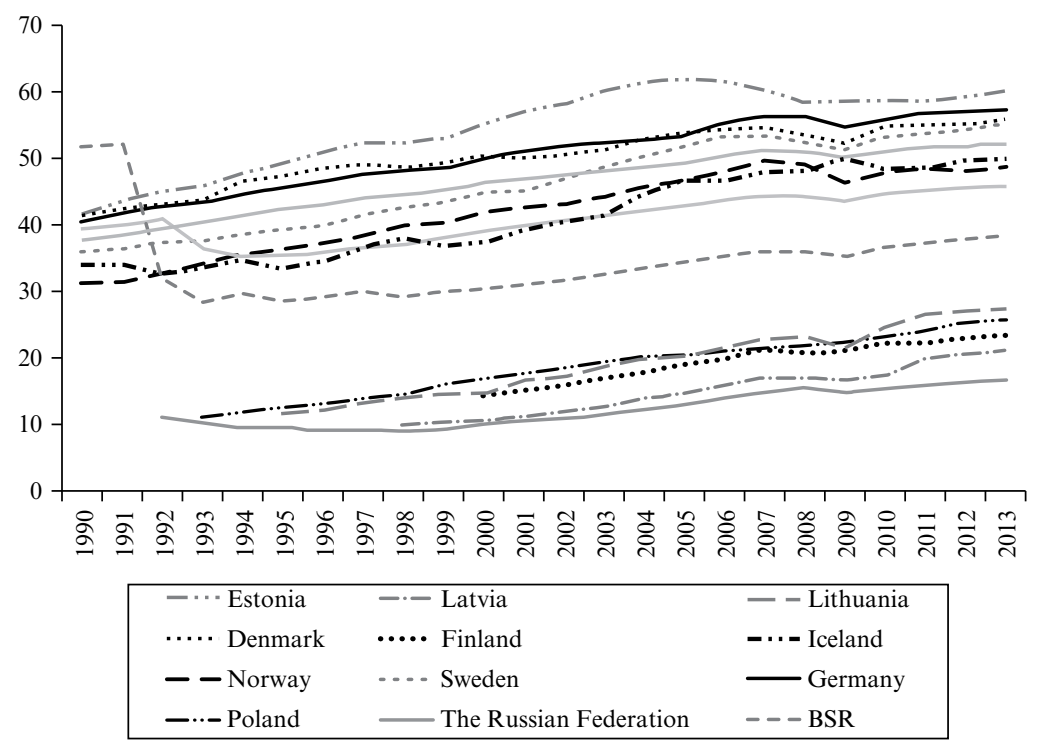

Note $: \quad \mathrm{BSR}=$ Baltic Sea Region; EKS $=$ Estonian Kroons; EU = European Union.

Source: Total Economy Database, The Conference Board.

Figure 2.8 Productivity (gross domestic product per hour worked, in 2013 EKS)

in competitiveness. The third section focuses on one particular policy and knowledge tool, the BSR cluster observatory, and how it has fared in terms of achieving policy objectives. Finally, we draw lessons that may be strongly related to the Greater Mekong Subregion and ASEAN Economic Community contexts in Asia.

\section{BUILDING BLOCKS AND TOOLS OF BALTIC SEA REGION COLLABORATION AND INTEGRATION: HOW THEY STACK UP AND CONNECT}

\subsection{Mapping of Tools}

The progress that has been made in strengthening cooperation and integration in the Baltic Sea Region (BSR) is a result of sound domestic foundations, which foster flows of goods, capital, people and ideas that are supported and enhanced by a number of knowledge platforms, policy 


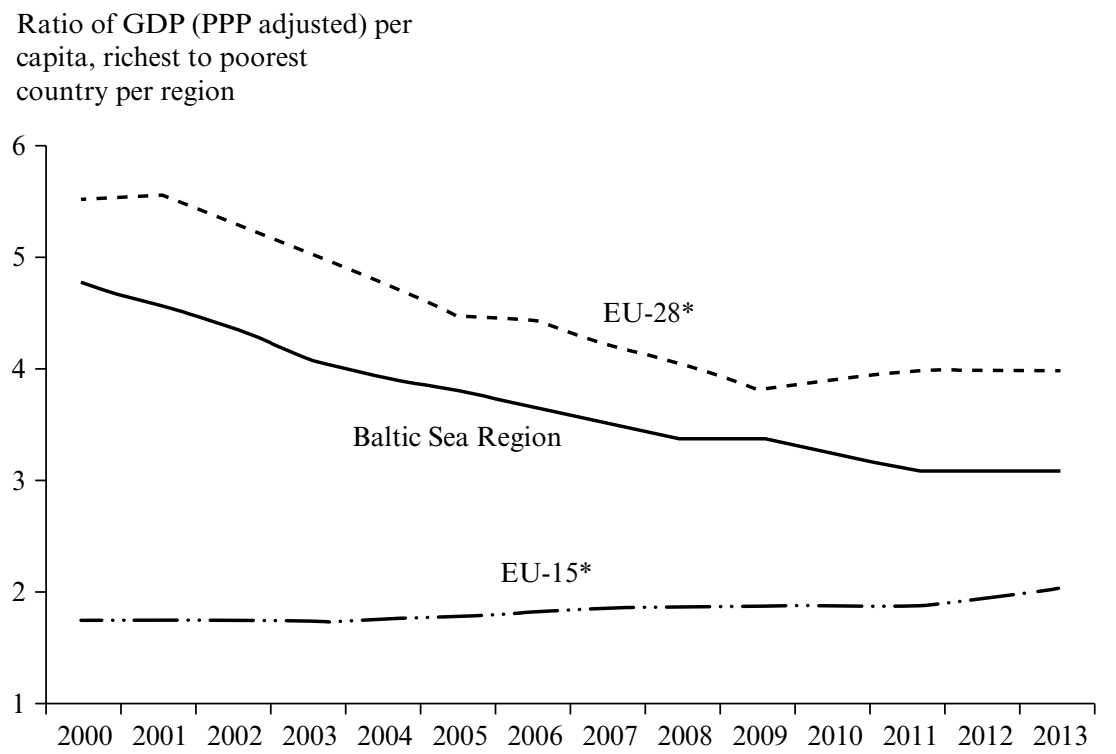

Notes:

Norway and The Russian Federation levels adjusted for natural resource sector; Luxembourg excluded.

$\mathrm{GDP}=$ gross domestic product; $\mathrm{EU}=$ European Union; $\mathrm{PPP}=$ purchasing power parity

Source: Conference Board (2014).

Figure 2.9 Prosperity dispersion within cross-national regions, 2000-13

instruments and organizational structures (for detail on policy tools see Appendix 2). This section introduces an overall categorization and mapping of tools for regional cooperation and integration, and presents some reflections on how they have functioned ${ }^{5}$ in the BSR and on the need for improvements.

The ultimate aim of these tools is to contribute to increased innovation capacity and productivity, and (in the longer term) growth and competitiveness for all countries in the BSR (see Figures 2.6 to 2.9). This book has already presented an array of toolboxes linked to an array of policy instruments aimed at maximizing impact (measured in terms of productivity, competitiveness, and cohesion). This section reflects on the function (and impact) of tools for regional integration by taking a closer look at the tools most closely related to cluster development and innovation collaboration, and that the EU, regional and national institutions have implemented at the BSR (macroregional) level (see Figure 2.12). 


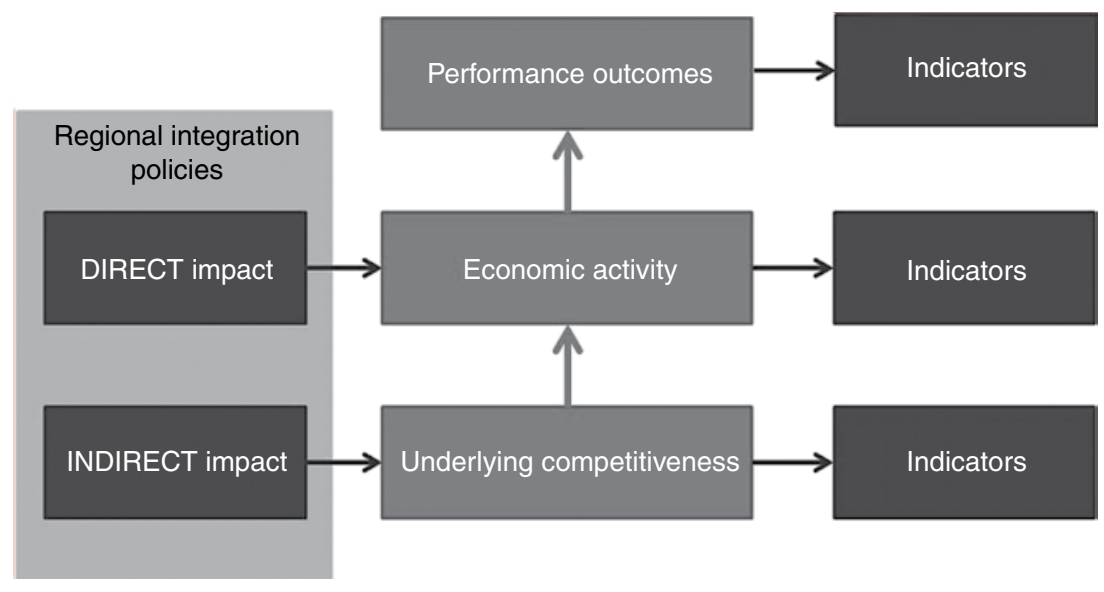

Source: Author.

Figure 2.10 Conceptual framework and indicators of regional integration

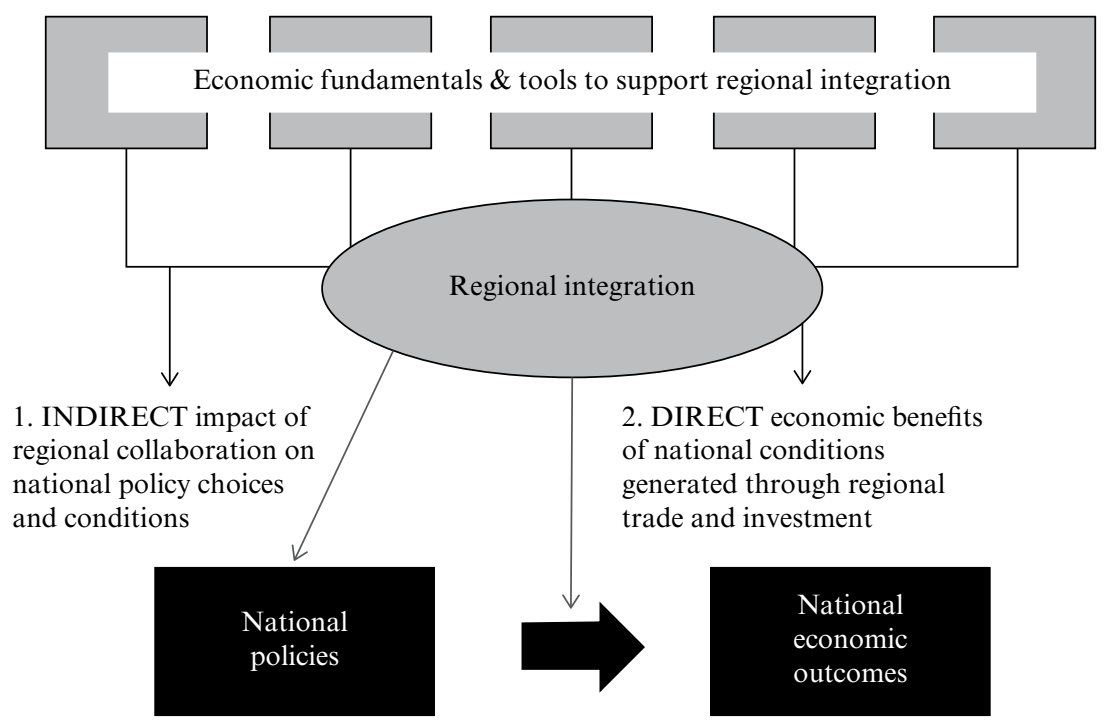

Source: Author.

Figure 2.11 Impact channels of regional economic integration 


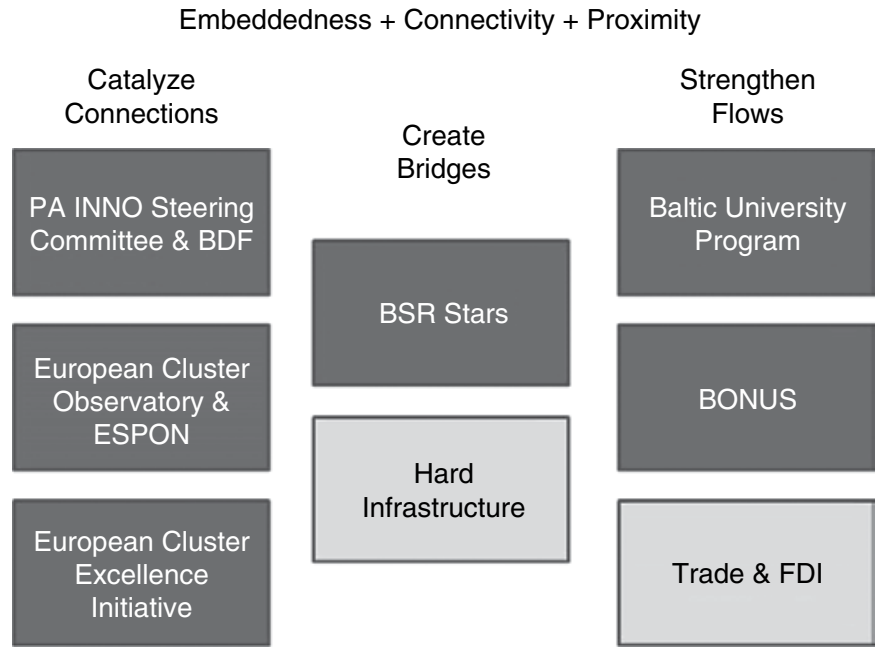

Note: $\mathrm{BDF}=$ Baltic Development Forum; $\mathrm{BSR}=$ Baltic Sea Region; FDI $=$ foreign direct investment; PA INNO = priority area innovation.

Source: Author.

\section{Figure 2.12 Tools for cluster development and innovation collaboration}

Tools are also mapped according to the level of implementation - where activities are decided, governed and (often) financed. Many tools for regional cooperation and integration are implemented by the EU. Other tools are implemented at the level of a smaller subgrouping of countries, at the level of the macro region (Baltic Sea Region) or the grouping of Nordic countries. Still other tools supporting international cooperation and integration are implemented at the national (or subnational) level.

Many of the tools for regional cooperation and integration provide strategic frames, discussion platforms, capacity building and other information or advisory support - helping to strengthen engagement and prioritization of collaborative activities, as well as the 'capacity to collaborate' (embeddedness). Other tools are focused on facilitating and developing more 'operational linkages' of people, knowledge and/or ideas, investments (FDI) and trade (connectivity).

The Priority Area Innovation (PA INNO) Steering Group is a platform for developing innovation strategy, and the Baltic Development Forum (BDF) is a platform for mobilizing action in prioritized areas. The European Observation Network for Territorial Development and Cohesion (ESPON) provides applied research and territorial evidence 
as an input to cohesion policy, and the European Cluster Observatory (ECO) has similar aims of providing a factual basis for policy development related to clusters. The European Cluster Excellence Initiative (ECEI) aims at developing skills of cluster managers, helping them provide high-quality services to cluster firms. All of these tools are aimed at improving the policy frame, developing capacity and mobilizing different actor groups. These tools help strengthen underlying competitiveness fundamentals.

BSR Stars aims to foster linkages between clusters and other specialized innovation environments through matchmaking events, coordinated calls and other activities to strengthen operational collaboration in these transnational teams. This tool is designed to create bridges (connectivity) among institutions located in different parts of the region to enhance collaboration among them.

The Baltic University Program strengthens East-West collaboration among universities through the joint development of courses and support to student mobility. BONUS is a BSR-level program that supports collaborative research projects on sustainable development. These tools strengthen the flow of people, ideas and collaborative development, and boost economic activities.

As described above, the eight tools have two different profiles. One group of tools ${ }^{6}$ is focused on policy and capacity development - strengthening underlying fundamentals. Another group of tools ${ }^{7}$ is focused on boosting operational collaboration - strengthening economic activities. This has implications on the key features (target groups, financing and timeframes) for the various tools.

The first group of tools targets policy makers and researchers providing input to policy makers. ${ }^{8}$ The tools support integration by providing data and knowledge that highlights the potential of integration and identifies areas in which to advance. The financing and timeframe of these activities is generally longer term, often driven by policy and/or program cycles (on a European level). Given that cluster development is not a separate policy area (but rather an integral part of regional development, research and innovation, and industrial policies), the tools that are more specifically focused on cluster development (ECO and ECEI) are not as strongly anchored to particular policy processes and programs. This is also reflected in levels of financial support (see Table 2.1, and details in Appendix 2). Whereas both ESPON and ECO have similar aims of providing a factual base for policy development and analysis of results and/or impacts, ESPON is linked to the area of cohesion policy (and has a corresponding mandate and financing for the seven-year program period), while ECO is not directly linked to specific policy processes or programs. 
The second group of tools targets companies, research organizations, university students and clusters - the actors that conduct the operational activities. The aim is to enable either collaboration or even movement across regional borders by reducing existing barriers. Many of the tools with more 'operational' objectives are structured as programs that provide short-term (up to three years) project financing. This often leads to limited resourcing (time and funds) and a lack of continuity in activities, making it very challenging to achieve more complex and longer-term goals. In addition, many of the tools operate as independent mechanisms, rather than as an integrated set of tools, reinforcing the limited impact of individual activities or projects.

Until the adoption of the EU Strategy for the Baltic Sea Region in 2009, there was no integrated strategic frame to prioritize action areas (and particular activities and projects within these). The strategy has provided a frame and action plan, which establish clearer interlinkages. But matching strategy with prioritized actions, and prioritized actions with corresponding resources (people and funding) to drive results, remains a struggle.

One of the main reflections on the BSR case is that the tools (even those with similar aims of cluster development and innovation collaboration) do not function together in an integrated fashion. It is important to have linkages between tools at all stages of the policy cycle (information and analysis to policy and program development to operational implementation to monitoring and evaluation and continual improvements to policy).

Informational and analytical tools have a stronger impact when linked directly to policy-making processes. When examining ESPON (and comparing it with the European Cluster Observatory), it is clear that ESPON is used as a key input to cohesion policy at the EU level, with a clear mandate, a significant budget and strong capacity to influence and evaluate policy.

Policy strategies also need linkages to operational programs. In the BSR case, the strategic policy level (embodied in the PA INNO Steering Committee) establishes priorities and catalyzes operational action through flagship projects. However, the policy strategy and priorities are not directly linked to budget allocations. Rather, financing for operational activities is provided through various EU programs, Nordic and national funds. This disconnect limits continuity in activities, and makes it challenging to achieve more complex goals and longer-term impacts.

Although there is no way to trace the combined impact of the tools and provide evidence of their contribution to longer-term performance outcomes, the fact that certain tools have existed for nearly 20 years continuing to drive new linkages and stronger flows - seems to indicate a useful contribution to regional integration. It is reasonable to expect that 


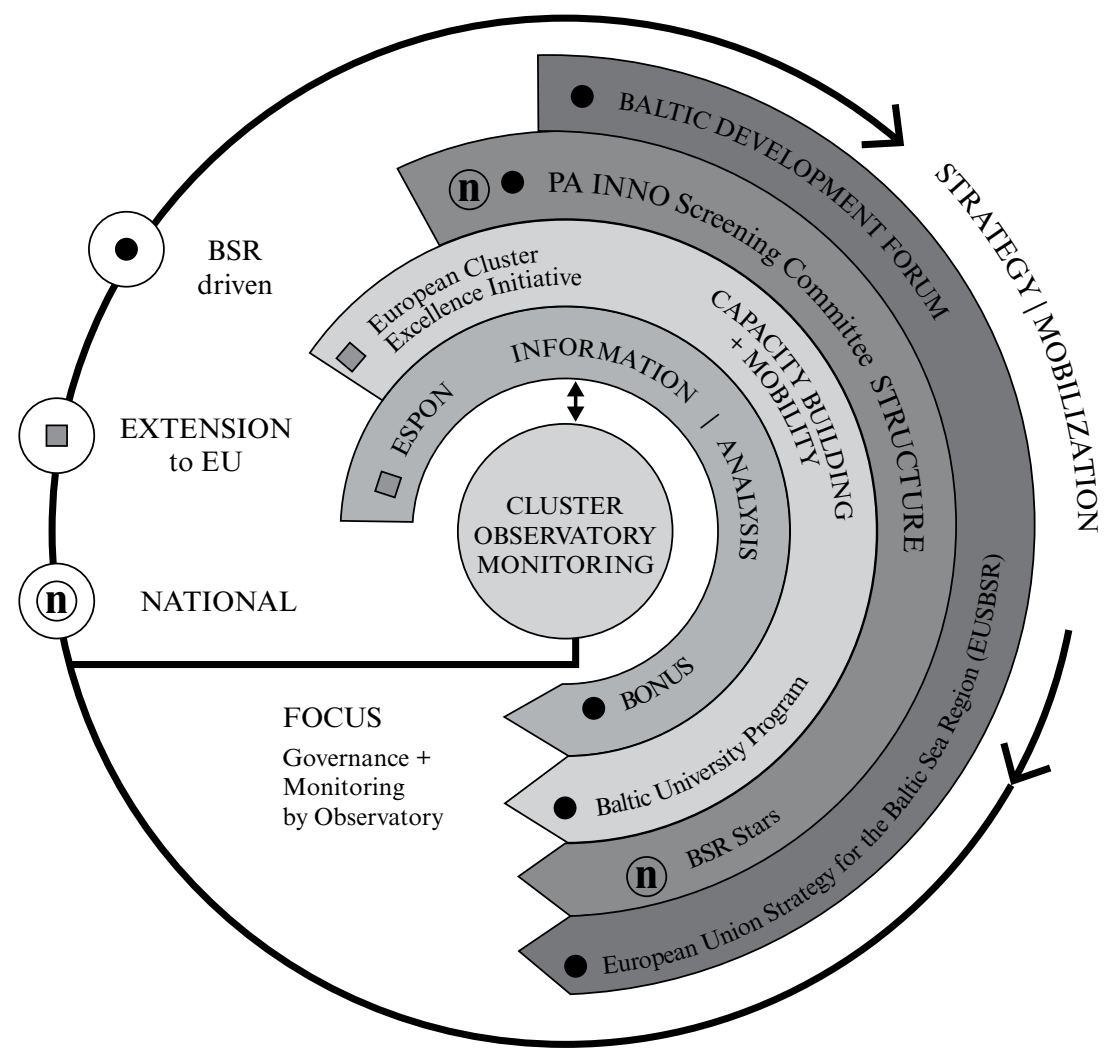

Note: $\quad \mathrm{BSR}=$ Baltic Sea Region; $\mathrm{EU}=$ European Union; $\mathrm{PA} \mathrm{INNO}=$ Priority Area Innovation.

Source: Author.

Figure 2.13 Integrated tools for cluster development and innovation collaboration

the various tools would have a more notable (and measurable) impact if they existed in a more integrated and transparent frame as sketched above (see Figure 2.13).

We expect the impact of the tools discussed here to manifest in a slower process of much deeper integration between the economies of this region, taking the form of many different kinds of flows. This has been visible through further trade integration, robust investment flows that even survived the shock of the crisis in the Baltic countries, and increasing ties in education and research. 


\section{TARGETS FOR REGIONAL COOPERATION AND INTEGRATION IN THE BALTIC SEA REGION}

\subsection{The Indicator and Measurement System for Innovation-driven Productivity Growth}

Network development and cohesion are central themes in BSR and in EU policy. The first theme is the translation of the common European market objective in transport infrastructure. From the early 1990s onward, the development of the Trans-European Transport Network (TEN-T) has been a central element in the European strategy to integrate markets and remove barriers to trade (see Appendix 2 for more details). The TEN-T network consists of a set of priority corridors for road and rail that connect different parts of Europe and that have priority with respect to transport infrastructure investments, in particular when European cofinancing is involved. Such co-financing can come from EU funds or from the European Investment Bank.

A second main theme in European policy relates to regional cohesion, or the policy to bring regions with lagging (economic) development toward the European average. The regional cohesion policy is behind a financing instrument like the Cohesion Fund, by which billions of euros are invested in infrastructure works such as roads, railways, water supply and sanitation projects, environment projects, etc.

For both the TEN-T program and the Cohesion Fund, strategic choices need to be made regarding priority fields of investment. These are generally made at intervals of seven years, in line with the European budget cycle. Every start of a new budget cycle gives the opportunity to redefine investment priorities between sectors, regions and types of projects.

The indicator and measurement system in the BSR is driven by EU-wide objectives. Knowledge tools have accordingly been developed to assess investment impacts. The socioeconomic and special impacts (SASI) model (for infrastructure impact, especially transport and corridor infrastructure) and ESPON (for cohesion impacts) are critical tools guiding policy and investment decisions.

The SASI model (Spit, 2014) is a recursive simulation model of socioeconomic development of regions in Europe, subject to exogenous assumptions about the economic and demographic development of the European Union as a whole, and transport infrastructure investments and transport system improvements in particular of the trans-European transport network. The SASI model differs from other approaches to modeling the impacts of transport on regional development by modeling not only 
production (the demand side of regional labor markets), but also population (the supply side of regional labor markets).

A second distinct feature of the model is its dynamic network database, maintained by RRG Spatial Planning and Geoinformation (a German consulting company) based on a strategic subset of highly detailed panEuropean road, rail and air networks, including major historical network changes as far back as 1981. The database also forecasts expected network changes according to the most recent EU documents on the future evolution of the trans-European transport networks. ${ }^{9}$

The ESPON 2013 database provides fundamental regional information provided by ESPON projects and EUROSTAT. This information can be used to support territorial development analysis at different geographical levels. The database contributes to a better understanding of the potentials and development perspectives of regions in the European context and globalized world, as its comparable data makes benchmarking of regions and cities feasible.

The ESPON 2013 database provides access to the following data categories: regional, local, urban, neighborhood (candidate countries), world, grid and historical data. Most of the datasets and information produced are publicly available and freely accessible. The datasets and indicators are related to the economy, finance and trade; population and living conditions; the labor market; education; health and safety; information society; agriculture and fisheries; transport and accessibility; environment and energy; science and technology; and governance and territorial structure.

\section{KNOWLEDGE TOOLS AND INDICATOR MAPPING}

Before this chapter distills policy lessons for utilizing an Asian Regional Economic Integration Observatory (AREIO) for RCI-driven productivity and inclusive productivity growth, it will now provide a short overview of best practice development observation platforms in use (for details refer to Appendix 3). There are a growing number of existing and developing observatory platforms, produced by development agencies, governments, universities, citizen advocacy groups, and companies (Table 2.3). Moreover, both interoperability and collaboration between these stakeholders are increasing. The reasons for this are varied. First, these developments are sourced in the context of an ever-increasing availability of data, which includes the digitization of legacy data products, as well as the development of new data products (Frankel and Reid, 2008; 
Table 2.3 Existing and related observatory and mapping platforms

\begin{tabular}{|c|c|c|}
\hline Organization & Project & Website \\
\hline \multicolumn{3}{|c|}{ Government } \\
\hline USAID & AidData & http://aiddata.org/maps \\
\hline $\begin{array}{l}\text { UK Department } \\
\text { for International } \\
\text { Development }\end{array}$ & $\begin{array}{l}\text { UK aid Development } \\
\text { Tracker }\end{array}$ & http://devtracker.dfid.gov.uk/ \\
\hline United Nations & $\begin{array}{l}\text { United Nations Global } \\
\text { Pulse }\end{array}$ & http://www.unglobalpulse.org/ \\
\hline $\begin{array}{l}\text { World Health } \\
\text { Organization }\end{array}$ & $\begin{array}{l}\text { Global Health } \\
\text { Observatory }\end{array}$ & http://www.who.int/gho/en/ \\
\hline European Union & $\begin{array}{l}\text { European Cluster } \\
\text { Observatory: Clusters at } \\
\text { Your Fingertips }\end{array}$ & $\begin{array}{l}\text { http://www.clusterobservatory. } \\
\text { eu/index.html }\end{array}$ \\
\hline European Union & $\begin{array}{l}\text { European Observation } \\
\text { Network for Territorial } \\
\text { Development and } \\
\text { Cohesion (ESPON) } \\
\text { Mapfinder }\end{array}$ & $\begin{array}{l}\text { http://www.espon.eu/main/ } \\
\text { Menu_ToolsandMaps/ } \\
\text { OnlineMapFinder/ }\end{array}$ \\
\hline $\begin{array}{l}\text { European } \\
\quad \text { Commission }\end{array}$ & $\begin{array}{l}\text { Infrastructure for Spatial } \\
\text { Information in the } \\
\text { European Commission }\end{array}$ & http://inspire.ec.europa.eu/ \\
\hline $\begin{array}{l}\text { European } \\
\quad \text { Commission }\end{array}$ & $\begin{array}{l}\text { Eurostat: Regional } \\
\text { Statistics Illustrated }\end{array}$ & $\begin{array}{l}\text { http://ec.europa.eu/eurostat/ } \\
\text { statistical-atlas/gis/viewer/; } \\
\text { http://epp.eurostat.ec.europa. } \\
\text { eu/cache/RSI/\#?vis=nuts2. } \\
\text { economy }\end{array}$ \\
\hline $\begin{array}{l}\text { European } \\
\text { Environment } \\
\text { Agency }\end{array}$ & $\begin{array}{l}\text { Environmental Interactive } \\
\text { Maps }\end{array}$ & $\begin{array}{l}\text { http://www.eea.europa.eu/data- } \\
\text { and-maps/explore-interactive- } \\
\text { maps } \# \mathrm{c} 5=\& \mathrm{c} 0=5 \& \mathrm{~b} \text { start }=0\end{array}$ \\
\hline $\begin{array}{l}\text { United States } \\
\text { Federal Geographic } \\
\text { Data Committee }\end{array}$ & Geoplatform.gov & http://www.geoplatform.gov/ \\
\hline $\begin{array}{l}\text { Baltic Sea Region } \\
\text { observatory }\end{array}$ & $\begin{array}{l}\text { Hosted at European } \\
\text { Cluster Observatory }\end{array}$ & $\begin{array}{l}\text { Part of http://www. } \\
\text { clusterobservatory.eu/index. } \\
\text { html }\end{array}$ \\
\hline \multicolumn{3}{|c|}{ Citizen advocacy } \\
\hline InterAction & NGO Aid Map & http://www.ngoaidmap.org/ \\
\hline $\begin{array}{l}\text { Open Aid } \\
\text { Partnership }\end{array}$ & Open Aid Map & $\begin{array}{l}\text { http://www.openaidmap.org/ } \\
\text { index.php }\end{array}$ \\
\hline Development Gateway & & $\begin{array}{l}\text { http://www. } \\
\text { developmentgateway.org/ }\end{array}$ \\
\hline $\begin{array}{l}\text { Ground Truth } \\
\text { Initiative }\end{array}$ & Map Kibera & http://groundtruth.in/ \\
\hline
\end{tabular}


Table 2.3 (continued)

\begin{tabular}{lll}
\hline Organization & Project & Website \\
\hline \multicolumn{3}{c}{ Development agency } \\
\hline $\begin{array}{l}\text { United Nations } \\
\text { Development }\end{array}$ & $\begin{array}{l}\text { International Aid } \\
\text { Programme }\end{array}$ & http://open.undp.org/\#2014 \\
$\begin{array}{l}\text { African } \\
\begin{array}{l}\text { Development Bank } \\
\text { Group }\end{array}\end{array}$ & Map Africa & http://mapafrica.afdb.org/ \\
World Bank & World Bank Open Data, & http://data.worldbank.org/ \\
& Mapping for Results & \\
\hline & \multicolumn{1}{c}{ University or academic } \\
\hline $\begin{array}{l}\text { Harvard Business } \\
\text { School }\end{array}$ & Cluster Mapping & http://clustermapping.us/ \\
Stockholm School of & The Cluster Observatory & Part of http://www. \\
Economics, Center & & clusterobservatory.eu \\
for Strategy and & & \\
Competitiveness & & \\
\hline
\end{tabular}

Notes: $\quad$ ESPON $=$ European Observation Network for Territorial Development and Cohesion; NGO = non-government organization; UK = United Kingdom; USAID = United States Agency for International Development.

Source: Author.

Lohr, 2012; Mayer-Schönberger and Cukier, 2013; McAfee et al., 2012; Picciano, 2014; The Economist, 2010; United Nations, 2012). In both cases, the sources of these data are growing as the barriers for creating data anew or adding value to existing data are reducing.

Second, and critically, much of these data are available in open access formats and sharing of those resources in a community setting is now becoming common (Steiniger and Bocher, 2009). A central catalyst for these developments has been the emergence of open data that are free from licensing and exchange restrictions.

Third, fusion across datasets is now commonplace, as data are developed on open data standards and formats that are robust (and often supported by standards committees) and extensible (Egenhofer, 2002; Koperski and Han, 1995). Archiving and sharing of both data and their exchange formats is now relatively commonplace, with the result that users can fashion interoperability with relative ease (Goodchild and Hill, 2008). Moreover, tools for achieving data fusion (whether through geocoding, data integration, mapping, mash-ups, infographics, linking and brushing 
and so on) are also becoming more open, easy-to-use and standardized, often with minimal or no licensing costs (Sherman, 2008).

Fourth, the tools for developing and using portals of this nature, or the data that they contain, are much more accessible than ever before, due in part to the maturation of geovisualization (Dykes et al., 2005; Edsall, 2007; Tufte, 2001; Wilkinson and Friendly, 2009; Wood et al., 2007) and related human-computer interaction (Card et al., 1983) and user experience technologies (Garrett, 2010). Of significant relevance, here, is the idea that public users can now easily access, visualize, interpret, share and play with extensive datasets (huge in isolated size, and/or massive in expanse across subjects and domains). Maps and cartography have been instrumental in these developments, because of the ability of maps to synthesize, abstract, organize and communicate data and concepts across a wide range of sources, users and semantics (Newman et al., 2010; Reese et al., 2007).

Geovisualization (Andrienko and Andrienko, 2006; Dykes et al., 2005; Kraak, 2008; Orford et al., 1999; Thomas and Cook, 2005) leverages geography as the basis for interface design; user experience: display of data, attributes and relationships; scientific visualization; animation; and data compression. Together, they cast geography as the central mode of interaction with the system. Geovisualization is particularly important for the purposes of the proposed observatory (1) because of the significance of spatial attributes in providing unifying structure for the data; (2) because of the geographically disparate and heterogeneous nature of the likely data sources and users cases; (3) because of the significance of geography in providing context for the system and its use; and (4) because the system provides a common organization scheme, given that it has a broad, and likely growing, set of users.

All of the existing observatory systems noted in Table 2.3 rely on cartography as the main scheme for visualization and interaction. This is one form of geovisualization, although more could be done to expand on the interface systems that have been developed thus far (Lee et al., 2002), particularly if ADB is to leverage an AREIO to enable and empower particular policy-making pathways and decision support systems atop its own unique user base; data; indicators; policy instruments; and strategies and goals for broadening participation, building on existing and developing new capacity, and prioritizing activities. ADB is also relatively distinct from existing observatory platforms in its ambitions to dock the observatory with models, which will lend the observatory significant 'what-if' capabilities, requiring special consideration.

A dedicated visualization strategy therefore must be considered as an integral part of the observatory's system design, which should involve: 
1. identifying the existing 'gold standard' user base for the observatory in this study, for example, but also through a review of ADB's own needs and that of its partner groups;

2. identifying occasional users of the observatory, particularly users of other, related information systems, that might connect to the observatory, dock elements of their platforms with the observatory, or ingest portions of the observatory into their systems;

3. identifying users that do know about but do not currently use observatories, but which may achieve additional advice, capacity, efficiencies and engagement were they to begin using observatories;

4. identifying users who have not yet at all considered using observatories, either because they (a) are not aware of them, (b) do not know how to leverage them, or (c) (and this group is usually important to engage) because they are critical of them.

In each of the cases beyond the 'gold standard' use case, this user engagement exercise could only begin once the observatory is up-andrunning in prototypical form, as it requires that users interact with the system and convey its benefits and limitations. Additionally, the visualization strategy will also require an ongoing review of what data the system can accommodate, could accommodate, and ought to accommodate, which can only begin through an iterative process of usage, testing and solicitation of feedback.

\subsection{The Cluster Observatory Tool: Success Factors}

As the BSR experience demonstrates, an observatory is a useful knowledge tool to search evidence on innovation clusters and evaluate the consequence of different policies. The knowledge tool is instrumental not only as an academic and statistical tool, but also to support the development of better (fact-based) cluster policies. There is a demand for analysis (and tests of effectiveness) of cluster policies, and support to policy learning. The BSR cluster observatory has 74 socioeconomic indicators under five sections (see Figure 2.14): competitive drivers, fundamentals, outcome, intermediate performance, and cluster indicators. Cluster indicators cover 41 industrial sectors. The observatory also emphasizes the role of innovative industries. There are three categories of innovation sectors: creative and cultural industries, knowledge-intensive business, and life science are independently listed.

An observatory should be a data management center where socioeconomic data from different sources is standardized and stored in a database system. Since spatial patterns are critical in analysis, the data should also be 


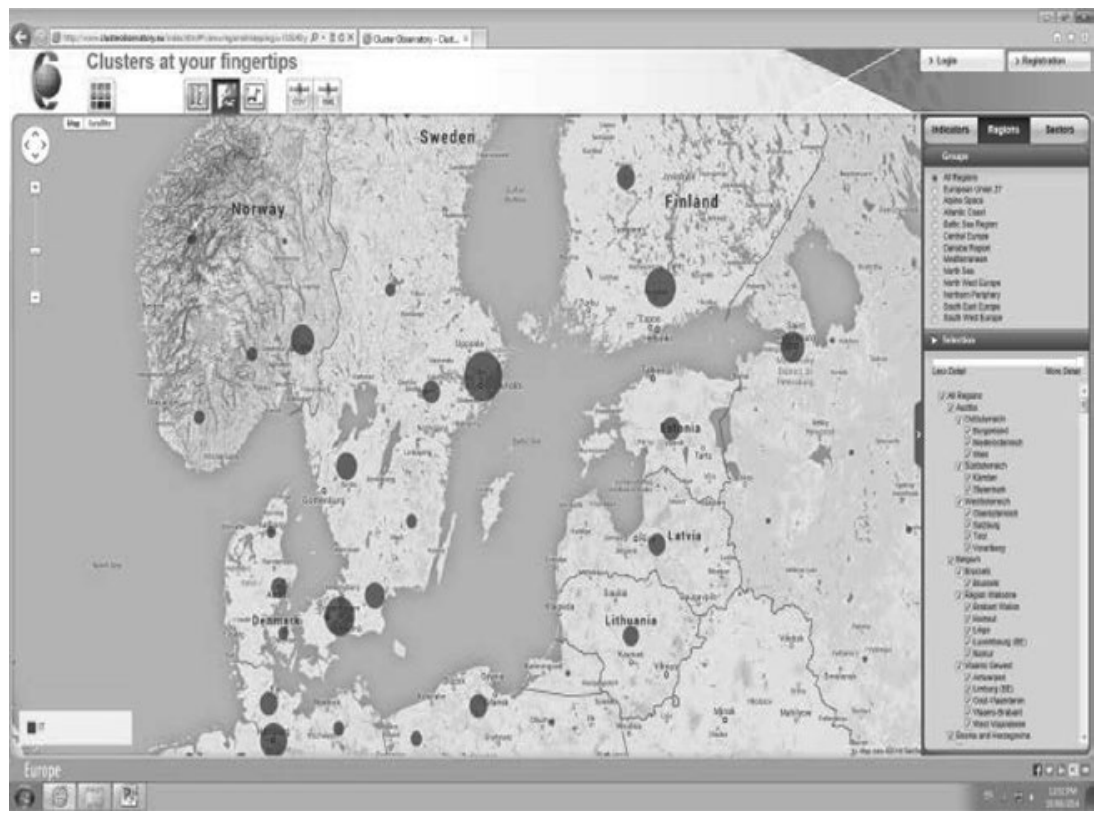

Source: European Cluster Observatory (http://ec.europa.eu/enterprise/initiative/cluster/ observatory/index_en.htm).

Figure 2.14 Interface of Baltic Sea Region cluster

organized and presented by location. The whole dataset also should have features of hierarchy corresponding to the hierarchical structure of administrative entities. The EU and BSR efforts have succeeded in establishing and maintaining an effective cluster observatory; however, challenges remain.

\subsection{The Cluster Observatory Tool: Challenges}

The cluster observatory is useful only if embedded in other data management tools (see Figure 2.13). These need to be assured complementarity to better capture elements of dynamic development processes in cluster and economic corridor ecosystems.

Analyses of standard cluster categories (based on traditional NACE [statistical classification of economic activities in the EU] codes and employment data) do not necessarily capture changing boundaries between sectors and industries. Supplementary analyses (and other indicators of 
industrial change and cross-sectoral flows) are in demand. The core statistics are complemented by more detailed analyses of patenting, mergers and acquisitions, and venture funding data.

Observatory effectiveness also depends on equivalent data availability and quality across a region. Data availability and quality vary across Europe despite the effort of Eurostat to harmonize the data collection process. While the basic indicators (employees and enterprises) are relatively easy to obtain, there is much more difficulty with productivity indicators, such as wages and value added.

\subsection{The Cluster Observatory Tool: Governance and Information Technology Infrastructure}

The Cluster Observatory (cluster mapping) has been developed over time through a series of project grants from the European Commission DG Enterprise and Industry. The observatory started as a mapping of clusters in $10 \mathrm{EU}$ member states in 2004, was expanded for all the EU in 2006, and further developed (in 2009 and 2011) to include data on the regional business environment, and an analysis of cross-sector fields of competency (or 'emerging industries'). The ongoing project grant (initiated in January 2014 for three years) is updating the statistical data and mapping, further developing data and information on clusters in 'emerging industries', as well as providing expanded analytical services for policy makers. The Cluster Observatory is one part (or work package) within a broader project (European Cluster Observatory II), led by Verband Deutscher Ingenieure (VDI/VDE-IT) in Germany, which also provides an analysis of European cluster trends, a regional ecosystem scoreboard, a 'stress test' of European cluster policies, and advisory support and policy learning activities for regional and national policy makers in Europe.

In more detail (until January 2014), the European Cluster Observatory website development and code-level support was procured from an external developer, while the team at the Stockholm School of Economics managed all the content and tracked the site's availability.

Some additional technical details:

- The computer systems used are a dedicated server running Ubuntu Linux, with Apache Tomcat as the web server and PostgreSQL as a database. As far as it is known, the developers used the Hibernate framework and many other open source and/or free solutions, such as OpenCMS for managing the content and Google Maps for mapping.

- The Stockholm School of Economics team had an internal person coordinating the overall design activities and an external company 
doing all the coding. The costs for development were approximately $€ 100000$ (\$108000) including three years of continuing improvements to the site. The costs for design (not graphical, but conceptual) are hard to quantify as it was done by people on a payroll as part of their everyday tasks.

- The annual cost of running the observatory is approximately $€ 500$ (\$540) and includes server hosting and domain names.

- The cost of data purchased for the website (see above) is about $€ 50000$ (\$54000) over five years (2009-13). (The cost of data is heavily dependent on the sources of data; much was attained for free, but some was very expensive.)

- Staff time is several person-hours per week, mainly for posting the news and moderating the user updates to the data on the website.

- In total, the European Commission invested $€ 2.5$ million (\$2.7 million) in project funding for the development and implementation of the European Cluster Observatory over this first fiveyear period. (As a point of comparison, approximately $\$ 4$ million (€3.7 million) was invested for developing and implementing the recently launched Cluster Observatory in the United States.)

The development of the system benefited from detailed and concrete specifications of functionality (detailed mockups, long discussions about how it should work), and a combination of extensive use of open code and tailor-made functions.

\section{POLICY LESSONS FROM THE BALTIC SEA REGION FOR THE GREATER MEKONG SUBREGION AND ASSOCIATION OF SOUTHEAST ASIAN NATIONS ECONOMIC COMMUNITY CONTEXT}

First, the specific policy instruments related to tools for regional integration need to be aligned with the key barriers towards changes at and behind the border. Policy makers might not understand the economic potential of integration. Entrepreneurs might not have the contacts in neighboring countries or information about their markets to spot opportunities. Government agencies aiming to support them might not have the necessary skills and information. Rules and regulations might need to be aligned to facilitate trade and growth. Capital might be missing to finance critical infrastructure links. For all of these, the Baltic Sea Region offers interesting tools and approaches worth studying.

Second, the BSR experience suggests a focus on activities that 'catalyze 
connections' (embeddedness). An Asian Regional Economic Integration Observatory (AREIO) can provide data and knowledge about the context, the benefits of integration, and win-win results that activities in specific areas can offer. This type of data is undersupplied in Asia, both on the regional level, where it is a public good, but often also at the national and subregional level, where the necessary capacity is missing. A regional observatory providing this data would fill an important void.

Third, BSR experience recommends the use of this data management platform to encourage a policy dialogue along three strategic issue areas in which specific activities can be taken:

1. Strengthening traditional global value chains oriented toward foreign markets by developing networks of strong clusters in the region. This is a process that has already started as a fully market-driven process. Governments can build on this, improving both their individual clusters and the way these clusters are connected as uniquely differentiated parts of global value chains. Here, the new activities would build on many existing policies but would aim to overcome the traditional zero sum competition between locations across Asia.

2. Assess investments and policy actions with a dedicated cross-border focus. Asia has a tradition of specific cross-border actions, like the growth triangle between Malaysia, Singapore and Indonesia, where policy changes and infrastructure investments were made in a coordinated fashion, focused on a specific geographic area close to the border. Governments can make these choices in a more fact-based way, if the data provided has sufficient granularity for the border regions. This is a somewhat narrow but very practical application of the data that can open the doors to wider usage.

3. Identify common competitiveness challenges and share learning about how to address them. The largest potential benefits would be derived from domestic upgrading of competitiveness triggered by regional integration. Common data on underlying competitiveness can provide a useful facilitating device to establish groups of officials looking at the implications of this data, and at ways to improve the relevant policies. Following what the European Union has called the method of open coordination, ${ }^{10}$ this would retain full sovereignty over decision making with national governments but enable them to learn from each other.

The focus on these three areas should inform the selection of indicators, the scope in terms of time, level of geography, industry and so on, and the combination of data with other activities to encourage data use and the creation of a community around an AREIO. 


\section{NOTES}

1. This amount includes only funds targeting the convergence objective (cohesion, regional development, and social funds), which are allocated to regions characterized by low levels of GDP and employment, and which aim to promote conditions conducive to growth. In addition, European Structural Funds are allocated to each country for territorial cooperation.

2. As part of the Competitiveness and Innovation Programme (CIP), a number of InnoNet projects were initiated to foster transnational innovation policy learning and implementation activities. The BSR InnoNet was one of these projects (running from 2006 to 2009).

3. See Solvell and Ketels (2006).

4. Additional information can be found in the BSR Stars profile description in Appendix 2.

5. Based on the details presented in the description of tools, found in Appendix 2, and on perspectives collected in the field study to Latvia and Lithuania.

6. Including the PA INNO Steering Group, BDF, ESPON, the European Cluster Observatory and the European Cluster Excellence Initiative.

7. Including BSR Stars, the Baltic University Program, and BONUS.

8. Although capacity building activities target all actor groups.

9. From the website of RRG, it is possible that no updates have been carried out since 2008. See http://www.brrg.de/index.php?language=en.

10. http://europa.eu/legislation_summaries/glossary/open_method_coordination_en.htm. 